\title{
Development of a thermal conductivity map of Stockholm
}

\section{Malin Malmberg Erwan Gloaguen José Acuña}

\author{
Jasmin Raymond \\ Claes Mellqvist
}

\author{
Lorenzo Perozzi \\ Gerhard Schwarz
}

\begin{abstract}
New methods have been suggested to spatially extend in situ thermal response test (TRT) assessments based on geostatistical analysis. These methods can be used to determine a stochastic distribution of the subsurface thermal conductivity beyond the test borehole on larger scales by interpolating the data with geostatistics, including sequential Gaussian simulations (SGS) used in the present study. This paper presents a simulated thermal conductivity map for Greater Stockholm in Sweden, based on the SGS method with input data from in situ measurements (TRT and DTRT). The geology of Stockholm is used as a background raster in the simulations, based on bedrock maps from the Geological Survey of Sweden (SGU). The resulting maps are compared with a point map of punctual ground thermal conductivity of Greater Stockholm earlier derived by SGU, compiled from laboratory data that were obtained by thermal conductivity scanning and modal analysis of surface rock specimens of the area.
\end{abstract}

\section{INTRODUCTION}

All ground source heat pump (GSHP) installations in Sweden deliver together around 15 TWh of heat per year and constitute the third largest renewable energy source in the country. When designing larger GSHP systems, consisting of multiple boreholes, it is today a usual practice to perform an in situ Thermal Response Test (TRT) to assess the thermal conditions of the ground. TRT assessments give, among others, a measure of the effective thermal conductivity of the subsurface. A research group in Japan (Fujii et.al. 2006) suggested a method to improve TRT and measure the thermal conductivity of the rock along the borehole depth using optical fiber cables. The method was further used in Sweden by KTH researchers (Acuña, 2013), within the Effsys2 and Effsys + research program and was named Distributed Thermal Response Test (DTRT).

Knowing the thermal conductivity allows for a more detailed evaluation of parameters such as the number of boreholes, their depth and the distance between the boreholes, and thereby facilitating to optimize the system. However, TRTs are spatially limited to the location of the borehole with a test radius of about 1 to $2 \mathrm{~m}$ (3.3 to $6.6 \mathrm{ft}$ ).

The use of geostatistical methods was suggested by Raymond et.al. (2017) with the objective of spatially extending TRT assessments beyond the test borehole on an urban district scale. The method, relying on stochastic simulations, has been performed in Greater Stockholm, Sweden, to map the subsurface thermal conductivity of the region based on the TRT and DTRT measurements from the company Bengt Dahlgren Geoenergi. Similar methodology has been used as for the first application of the method made in the St. Lawrence Lowlands geological provinces of Canada (Lorenzo et. al. 2016; Raymond et.al. 2017), with a few improvements. The bedrock map to be found in the

Malin Malmberg (malin.malmberg@bengtdahlgren.se) is a civil engineer at Bengt Dahlgren Geoenergi, Jasmin Raymond and Erwan Glaugen are proffessors at Institut national de la recherche scientifique, Lorenzo Perozzi is a postdoctoral fellow at Institut national de la recheche scientifique, Claes Mellqvist is geologist and Gerhard Schwarz is a geophysicist at the Geological Survey of Sweden and José Acuña is GSHP specialist at Bengt Dahlgren Geoenergi and researcher at KTH Royal Institute of Technology. 
Geological Survey of Sweden (SGU) database (SGU, 2018) is used in the simulations as a background raster to account for the geology of the area. It should be emphasized, as pointed out by Raymond et al. (2017), that the method does not replace TRTs, but it can be an alternative to anticipate TRTs reducing uncertainty in geothermal feasibility studies.

Based on the available TRT and DTRT data measured in situ, the resulting map partly reflects bulk thermal conductivity of the subsurface on the macro scale. A map of the ground thermal conductivity of the Greater Stockholm earlier developed by SGU (Schwarz et al. 2010, Erlström et al. 2016) and an upgraded version (SGU, unpublished) primarily describes the micro-scale. The SGU map was compiled from laboratory data that were obtained by the method of thermal conductivity scanning (TCS: Popov et al. 1999) and modal analysis of surface rock specimen in the area to evaluate mineralogy and calculate thermal conductivity according to the volume faction of minerals. Schwarz et al. (2010) classified the thermal conductivity of the bedrock in five groups, from 2.5 to $>4.5 \mathrm{~W} \mathrm{~m}^{-1} \mathrm{~K}^{-1}\left(1.4\right.$ to $>2.6 \mathrm{Btu}^{-}$ ${ }^{1} \mathrm{ft}^{-1}{ }^{\circ} \mathrm{F}^{-1}$ ), based on the bedrock map (scale: 1:50 000) of the Stockholm region (Persson et al. 2001).

The map obtained from geostatistical simulations based on in situ thermal conductivity data (macro scale) and the map earlier derived by SGU drawn from TCS and modal data are compared and their features are discussed.

\section{METHODOLOGY}

The subsurface thermal conductivity was initially evaluated in situ with TRTs or DTRTs. For this project TRT and DTRT results have been used from ongoing installations in the Stockholm area and being performed by Bengt Dahlgren AB. Fifteen tests (TRT and DTRTs) have been completed by Bengt Dahlgren AB by the time this study was done. These were performed in the Stockholm region and are the ground for the work presented in this paper. All tests have been carried out under controlled conditions with a known and constant water flow and heat injection rate, as recommended by national and international best practices. The power is supplied to the boreholes through the heat carrier fluid circulated in the BHE with a constant flow rate. The effective thermal conductivity of the ground and the borehole resistance was determined from the continuous measurements of the temperature of the circulating fluid at the inlet and outlet of the collector.

The rock thermal conductivity map was achieved with interpolation using sequential Gaussian simulations (SGS: Goovaerts 1997). A Cartesian grid over the study area $\left(527 \mathrm{~km}^{2} ; 130224\right.$ acres) was initially created to divide the area in 53000 cells with a cell size of $100 \times 100 \mathrm{~m}(328 \times 328 \mathrm{ft})$. When performing the SGS algorithm, a random path visiting all the cells is created, as illustrated in Figure 1. Cells containing known thermal conductivity data from in situ TRTs are considered static. Along the random path, new cells are selected and assigned interpolated simulated value estimated by simple kriging under Gaussian hypothesis. The simulated values are then used as conditioning data. The map data are complete when all cells have been visited once and the algorithm assures the simulations to be spatially correlated. For one set of input parameters, multiple realizations can be generated by using different random paths and random seeds (Figure 1). 

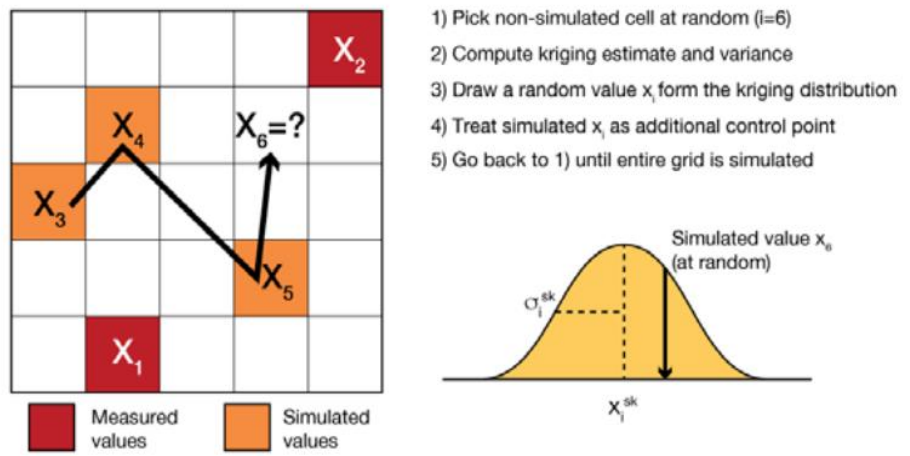

Figure 1 Schematic illustration of the SGS algorithm used to simulate the distribution of host rock thermal conductivity (Perozzi et al. 2016).

The SGS is a variogram based algorithm. The variogram informs about the spatial variability of the studied data and their distance correlation. As a limited amount of static data (in situ TRT assessments) was used for the simulations in this project, it was difficult to calculate the variogram and to know how the data correlates with distance. Hence three different variogram models were used. The three different variogram models (Table 1) have been consequently used to obtain a spectrum of potential variance of the subsurface thermal conductivity in the studied area: ordinary variance, extreme variance and smooth variance. The different variograms were created by changing the range, which corresponds to the maximal distance where a correlation can be observed of the studied variable. The maps can, however, be updated when a relevant amount of new measured data will be collected.

The assumptions made was that Scenario 1, with the "ordinary variance", is the scenario with the highest probability to describe the spatial variability in the area, while Scenario 3, with a very smooth variance has a lower probability as the geology is not expected to be continuous with distance. The different scenarios were hence indirectly weighted by performing a larger number of realizations for Scenario 1 and fewer for Scenario 3. An exponential model and an azimuth angle of $110^{\circ}$ (defining an anisotropy ellipsoid) were used in all three scenarios. The azimuth angle was chosen owing to the geological structures observed in the northern part of the studied area (Figure 2).

Table 1. The Three Variogram Models Used for The Geostatistical Simulations

\begin{tabular}{cccc}
\hline Parameter & $\begin{array}{c}\text { Scenario 1 (ordinary } \\
\text { variance) }\end{array}$ & $\begin{array}{c}\text { Scenario 2 (extreme } \\
\text { variance) }\end{array}$ & $\begin{array}{c}\text { Scenario 3 (smooth } \\
\text { variance) }\end{array}$ \\
\hline \hline Model & Exponential & Exponential & Exponential \\
Range 1 [m] (ft) & $10000(32808)$ & $5000(16504)$ & $15000(49212)$ \\
Range 2 [m] (ft) & $6000(19685)$ & $3000(9842)$ & $10000(32808)$ \\
Azimuth [degrees] & 110 & 110 & 110 \\
\# of realizations & 500 & 300 & 200 \\
\hline
\end{tabular}

The bedrock geology in the Stockholm region mainly consists of intrusive granitic rock and a metamorphic metagraywacke of sedimentary origin. Based on the bedrock geology, regions were created dividing the lithologies in the two groups: granitic rocks and metagraywacke (Figure 2). Triangular distributions of the thermal conductivity of granite and metagreywacke were assigned to reproduce the characteristics to the region. The thermal conductivity for granite varies between 2.9-4.2 $\mathrm{W} \mathrm{m}^{-1} \mathrm{~K}^{-1}\left(1.7-2.4 \mathrm{Btu} \mathrm{hr}^{-1} \mathrm{ft}^{-1}{ }^{\circ} \mathrm{F}^{-1}\right)$ with a mean value of about $3.5 \mathrm{~W} \mathrm{~m}^{-1} \mathrm{~K}^{-1}(2.0 \mathrm{Btu} \mathrm{hr}$ $\left.{ }^{1} \mathrm{ft}^{-1}{ }^{\circ} \mathrm{F}^{-1}\right)$ (Nordell 1994). The thermal conductivity specified for the triangular distribution of the granitic rocks in the area was averaged to a value of $3.5 \mathrm{~W} \mathrm{~m}^{-1} \mathrm{~K}^{-1}\left(2.0 \mathrm{Btu} \mathrm{hr}^{-1} \mathrm{ft}^{-1}{ }^{\circ} \mathrm{F}-1\right)$, assuming a range of $2.0-4.5 \mathrm{~W} \mathrm{~m}^{-1} \mathrm{~K}^{-1}(1.2-$ 2.6 Btu hr-1 $\left.\mathrm{ft}^{-1}{ }^{\circ} \mathrm{F}^{-1}\right)$. The average for the metagreywacke was taken as $3.0 \mathrm{~W} \mathrm{~m}^{-1} \mathrm{~K}^{-1}\left(1.7 \mathrm{Btu} \mathrm{hr}^{-1} \mathrm{ft}^{-1}{ }^{\circ} \mathrm{F}^{-1}\right)$ with a range of 1.5 - $4.0 \mathrm{~W} \mathrm{~m}^{-1} \mathrm{~K}^{-1}\left(0.9-2.3 \mathrm{Btu} \mathrm{hr}^{-1} \mathrm{ft}^{-1}{ }^{\circ} \mathrm{F}^{-1}\right)$. The simulations were performed within the region with respect to the 
triangular distributions. Hence, two simulations were required, one for granitic rocks and one for metagreywacke, which were later merged together. A moving average was calculated as a postsimulation within a $200 \mathrm{~m}$ width using spatial filtering to smooth edging effects between the regions (Figure 2; white areas).

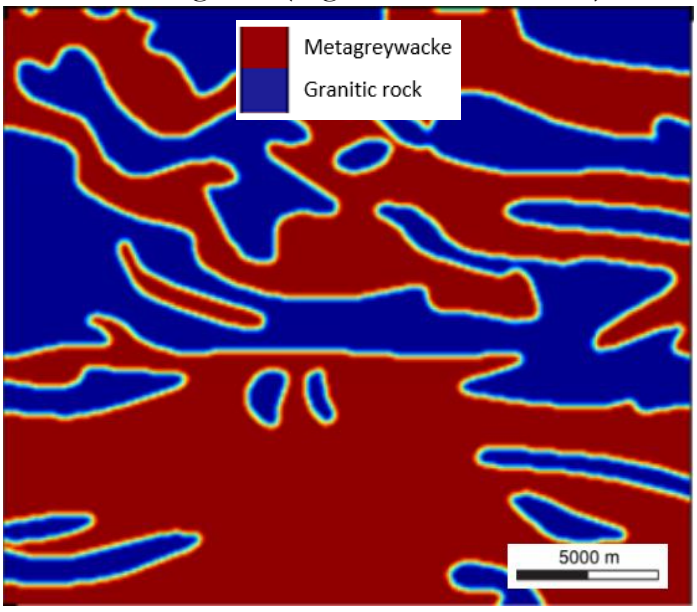

Figure 2 Grouped lithologies, metagraywacke and granitic rocks, used for the SGS in the studied region of Greater Stockholm $(21.5 \times 24.5 \mathrm{~km})$.

In total, 1000 realizations were simulated, considering indirect weighting of the three scenarios. Scenario 1 , Scenario 2 and Scenario 3 were assigned 500, 300 and 200 realizations, respectively (Table 1). The result obtained is 1000 equiprobable maps showing the distribution of the host rock thermal conductivity. Based on these, the total mean and total variance was calculated.

Finally, the generated maps were compared to those produced by the Geological Survey of Sweden (SGU). These maps were compiled from laboratory data obtained by thermal conductivity scanning (TCS: Popov et al. 1999) and modal analysis of surface rock specimens of the area.

\section{RESULTS}

The geostatistical method described above was used to spatially extend the thermal conductivity of the subsurface host rock in a $527 \mathrm{~km}^{2}$ (130 224 acres) area of Greater Stockholm (Figure 3a). The results are shown in 53000 pixels, each covering $100 \times 100 \mathrm{~m}(328 \times 328 \mathrm{ft})$. One thousand equiprobable realizations have been produced, divided as three scenarios with three different variances. Figure $3 \mathrm{~b}, 3 \mathrm{c}$ and $3 \mathrm{~d}$ show the result of single stochastic realizations of scenarios 1, 2 and 3, respectively. Figure $3 \mathrm{e}$ and $3 \mathrm{f}$ present the mean and the standard deviation of the 1000 realizations, respectively. It can be noticed that for all scenarios, and for the mean of the 1000 realizations, the thermal conductivity is higher in the areas associated to granitic rock, especially in the northern regions. This is due to the bedrock geology which was used as a background raster in the simulations. There is also a higher number of values of high thermal conductivity in the northern areas from the static in situ TRT measurements. Comparing the three single realizations in Figure 3b, 3c and 3d (Scenarios 1, 2 and 3), it can be observed that the result is smoothest for Scenario 3, while the variance is highest for Scenario 2, a result of the different ranges applied for the variograms in each Scenario (Table 1). One single value affects the neighboring cells in the SGS depending on the chosen range for the variogram. 
a) Thermostratigraphy and static TRT data

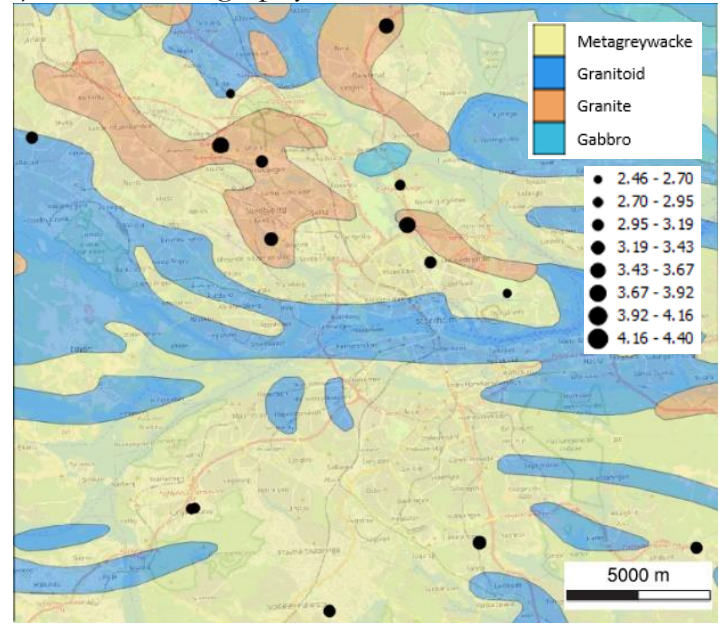

c) Single stochastic realization, Scenario 2

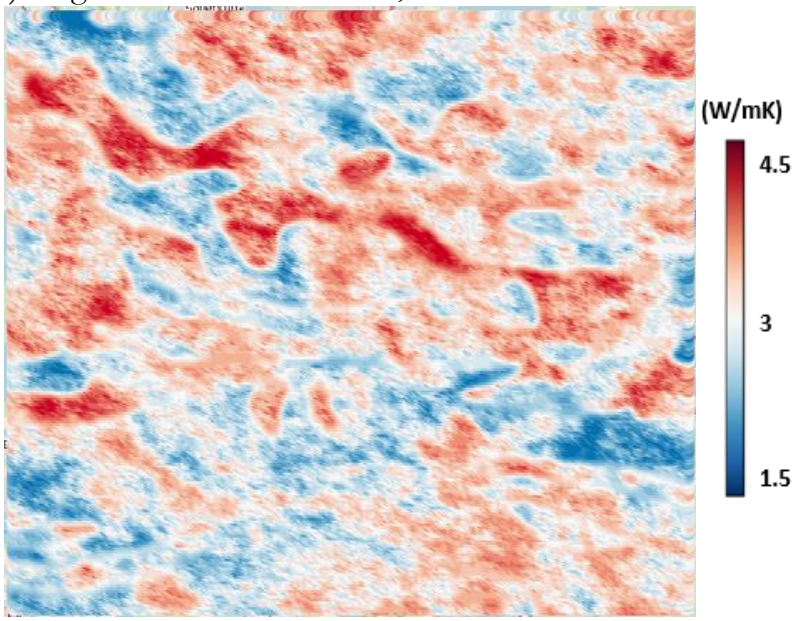

e) Mean from 1000 realizations

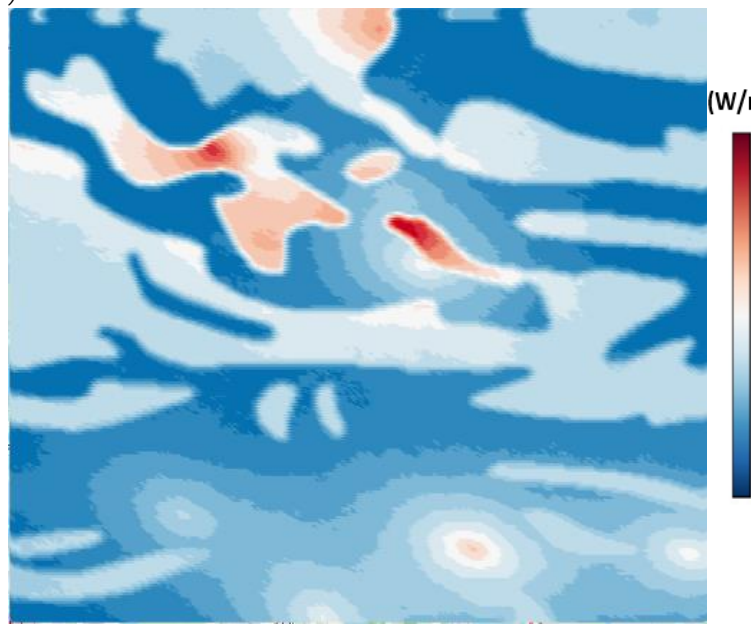

Figure 3

Sequential Gaussian simulations of the bedrock thermal conductivity in Greater Stockholm $(21.5 \times 24.5 \mathrm{~km})$.
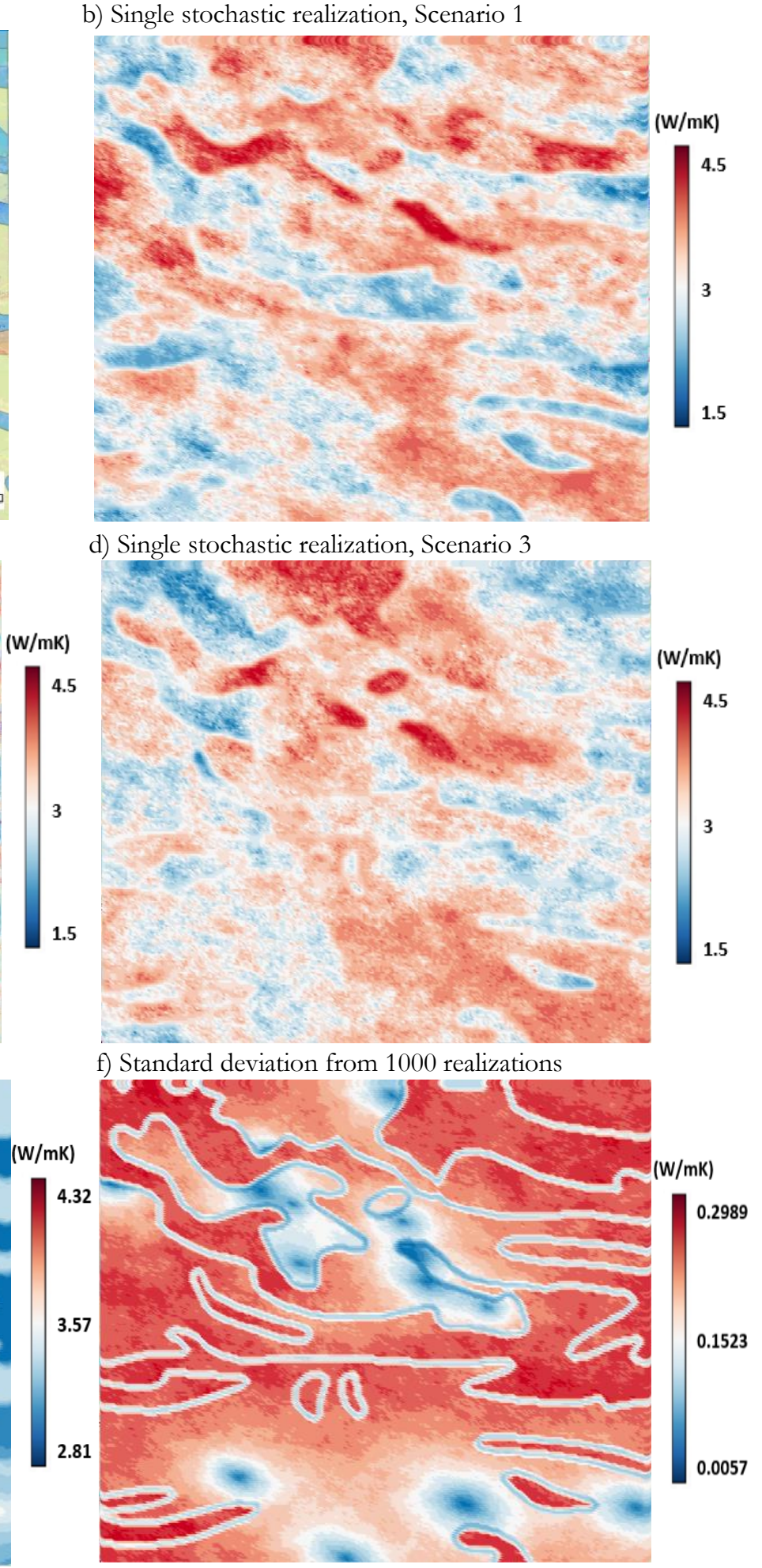

d) Single stochastic realization, Scenario 3

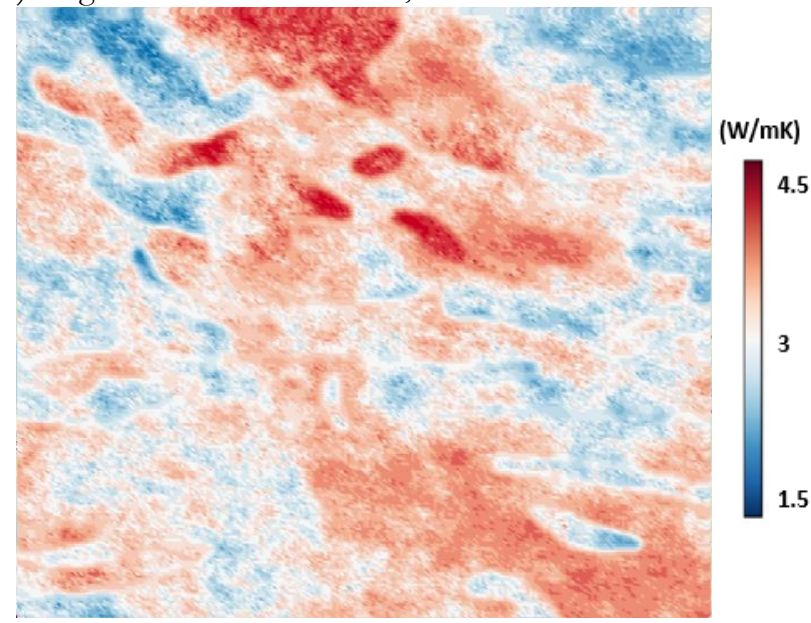

f) Standard deviation from 1000 realizations 
Results of an earlier map developed by SGU (unpublished) is shown in Figure 4. The map was originally prepared for the Greater Stockholm area $\left(2500 \mathrm{~km}^{2}\right)$ but was cropped to the area considered for the geostatistical simulations to allow a direct comparison for this study $\left(527 \mathrm{~km}^{2} ; 130224\right.$ acres). The point map shows data resulting from laboratory TCS evaluation and modal analysis of rock samples. The map includes a classification of the subsurface host rock from 2.4 to $\geq 4.5 \mathrm{~W} \mathrm{~m}^{-1} \mathrm{~K}^{-1}\left(1.4\right.$ to $\left.>2.6 \mathrm{Btu} \mathrm{hr}^{-1} \mathrm{ft}^{-1}{ }^{\circ} \mathrm{F}-1\right)$ divided as five groups or thermal subunits. The range of the classes is based on the bedrock map over the Stockholm region showing the mineral distribution in the area (Persson et al. 2001).

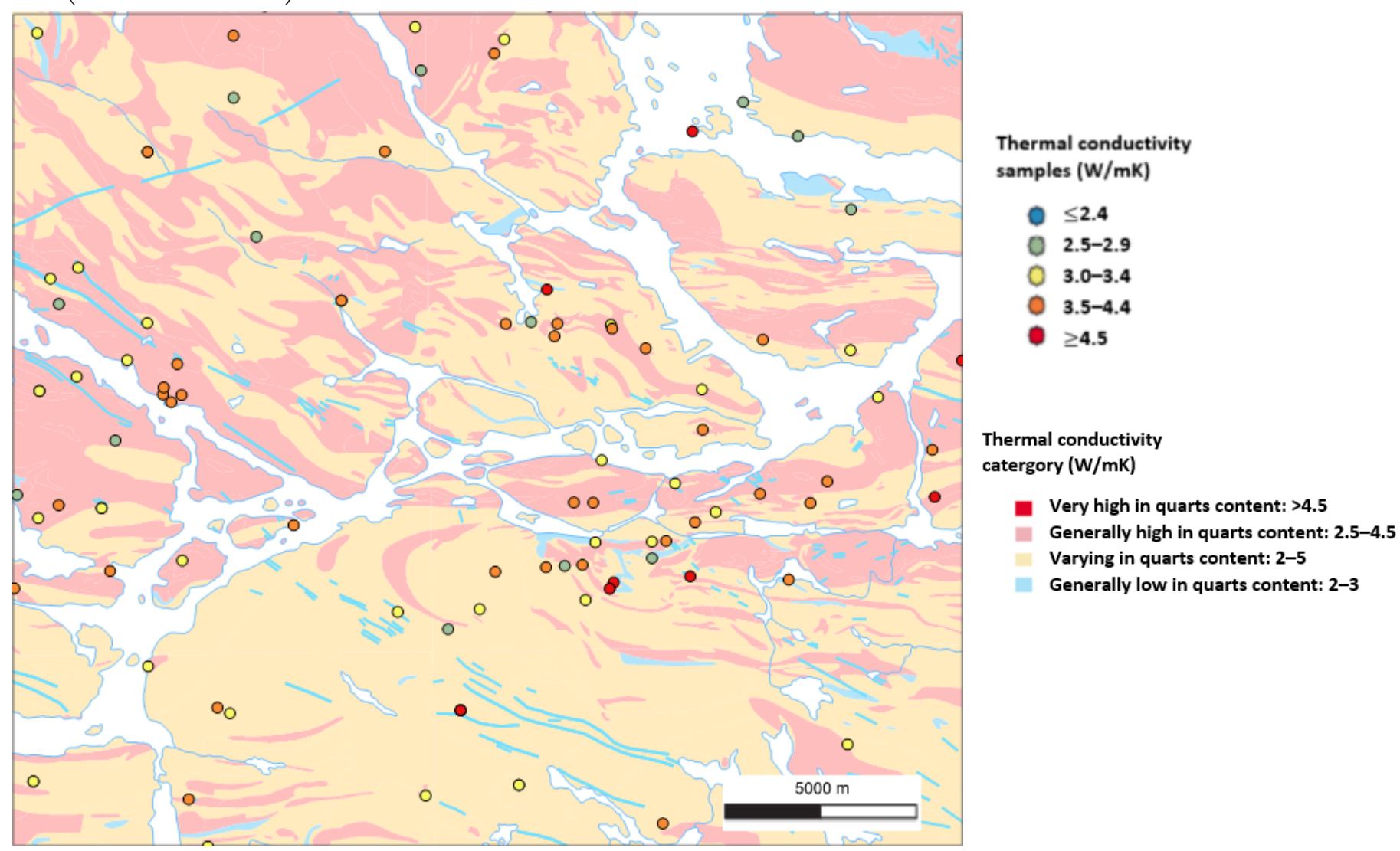

Figure 4 Point map of bedrock thermal conductivity in Greater Stockholm $(21.5 \times 24.5 \mathrm{~km})$ evaluated from laboratory analysis by SGU (unpublished data) and plotted over thermal conductivity groups based on the geological map of Persson et al. (2001).

\section{DISCUSSION}

The resulting geostatistical map from Scenario 1 (Figure 3b), assumed to be the scenario with the highest probability to explain the spatial variance in the area, has been combined with the SGU thermal conductivity point map (Figure 4) to allow comparison (Figure 5). The range for the thermal conductivity differ between the two maps when comparing Figure 4 and Figure 5. This is because the triangular distributions of the thermal conductivity of granite and metagreywacke assigned for the two categories and used for the geostatistical simulations (Figure 5) differ from the geological categories used for the SGU map (Figure 4). Some correlations can be seen, regardless of this factor, when comparing areas with high and low thermal conductivity. Higher values are observed in the north of the map compared to the southern parts. 
Factors affecting the field scale mapping with in situ assessments, such as groundwater flow, permeability and structural deformation of the bedrock can influence the resulting thermal conductivity distribution, which was not considered to develop the SGU point map. Results illustrated by the SGU map are micro-scale variations based on thermal conductivity data measured directly on rock samples or calculated from mineral composition determined under the microscope. The SGU data include important information regarding the mineralogy and distribution of different rock types and is based on a large quantity of laboratory analysis available at SGU. In situ TRTs, on the other hand, result in the effective thermal conductivity, which includes the impact of external factors - although TRT analysis is normally performed assuming heat transfer by conduction only. Thereby, a TRT result does not present the thermal conductivity of a specific rock sample but a mean or bulk value including many influencing factors along an entire borehole, though the effective rock volume is limited. Further work has to be done to adequately compare in situ TRTs with laboratory measurements and evaluate the field scale effects that is associated to the maps.

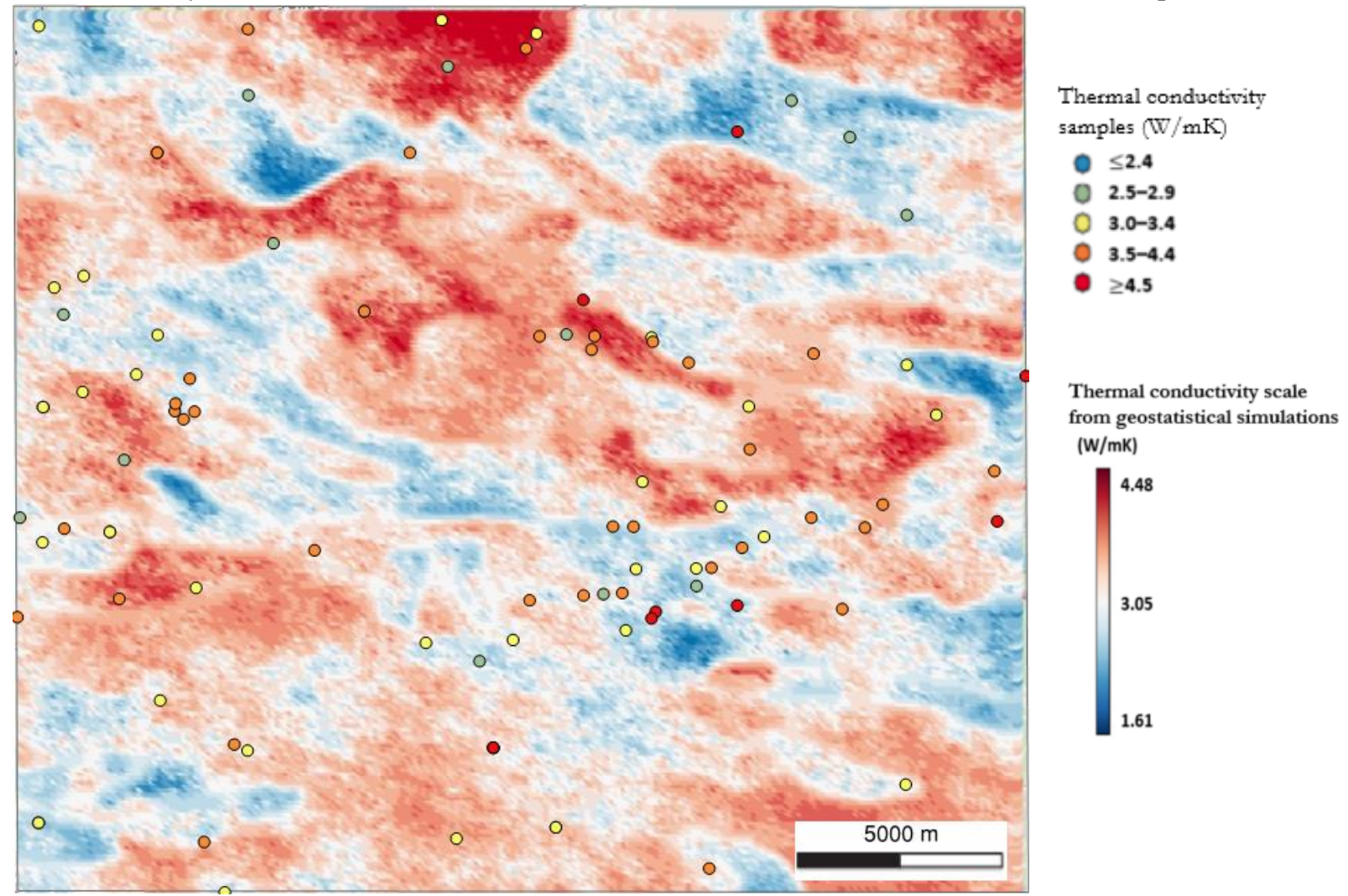

Figure 5 Combined bedrock thermal conductivity map of Greater Stockholm $(21.5 \times 24.5 \mathrm{~km})$ with superposition of a SGS realization based on in situ TRTs (scenario 1) as transparent on top of the point map derived from SGU laboratory analysis (Schwarz et al. 2010, SGU, unpublished).

\section{CONCLUSIONS}

An attempt to map the distribution of subsurface thermal conductivity is presented in this study for the Stockholm region, based on geostatistical simulations using the methodology suggested by Raymond et al. (2017). The proposed method was improved by using the bedrock geological map available from SGU as a background information for the SGS simulations of TRT data. In a separate study, SGU had earlier developed a point map from laboratory analysis of surface rock samples evaluated with TCS and modal analysis over the Greater Stockholm (Schwarz et al. 2010). 
In situ TRTs and the analyses of hand specimens are spatially limited to individual boreholes and rock samples, respectively. This is a limitation for the GSHP industry as repeating TRTs or outcropping bedrock accessible for collecting samples are required. Using interpolation methods from geographically unevenly distributed TRTs or hand specimen samples to illustrate variations in the bedrock can help to picture large-scale distribution of thermal conductivity but may not be adequate to identify its local heterogeneities. Thermal conductivity is linked to microscopic variation of mineral content observed in rock specimens, but also to macro effects, like, e.g., the groundwater flowing in the bedrock. Both mapping approach, from geostatistical simulations and modal and TCS analysis, are based on the geology of Stockholm available from SGU. The final projections are thereby considering the different boundaries of the bedrock distribution.

The two map types were derived from different approaches and map scales that could be combined to improve the quality and reliability of the maps. The classification made by SGU for the thermal conductivity for different regions could be used as a background raster for new geostatistical simulations. In addition, an increased number of TCS and modal data would enable calibration of the mineral distribution and additional information could be gained addressing field scale effects of thermal conductivity measurement.

In this paper, three variogram scenarios for thousand realizations obtained from the geostatistical simulations were presented. Some maps could show an equiprobable higher difference in thermal conductivity to the map developed by SGU, while other show a lower difference. Comparing the three different scenarios presented in Figure 3 (b, c and

d) changes in the variogram model result in different map variances. An increased number of TRT data could improve the variogram model used for the geostatistical simulations which would increase the reliability of the maps.

\section{Subscripts}

DTRT $=$ Distributed thermal response test
GSHP $=$ Ground source heat pump
SGS $=$ Sequential Gaussian Simulation
TCS $=$ Thermal conductivity scanning
TRT $=$ Thermal response test

\section{REFERENCES}

Acuña, J. 2013. Distributed thermal response tests - New insights on U-pipe and Coaxial heat exchangers in groundwater-fi lled boreholes. KTH Royal Institute of Technology, Division of Applied Thermodynamic and Refrigeration, Stockholm.

Erlström, M., C. Mellqvist, G. Schwarz, M. Gustafsson and P. Dahlqvist. 2016. Geologisk information för geoenergianläggningar: en översikt. Sveriges geologiska undersökning, SGU rapport 2016:16, 56 p.

Fujii, H., H. Okubo and R. Itoi. 2006. Thermal Response Tests Using Optical Fiber Thermometers. GRC Transactions 30: 545-51.

Geological Survey of Sweden, SGU. 2018. Berggrund 1:1 miljon. https://www.sgu.se/produkter/geologiska-data/vara-dataper-amnesomrade/berggrundsgeologiska-data/berggrund-11-miljon/

Goovaerts, P. 1997. Geostatistics for Natural Resources Evaluation. New York, USA: Oxford University Press.

Nordell, "Borehole heat store design optimization," Luleå University of Technology, Luleå, 1994.

Perozzi, L., J. Raymond, S. Asselin, E. Gloaguen, M. Malo and C. Bégin. 2016. Simulation géostatistique de la conductivité thermique: Application à une région de La communauté métropolitaine de Montréal. Quebec City, Canada: Institut national de la recherche scientifique - Centre Eau Terre Environnement, R1663, http://espace.inrs.ca/3374/1/R001663.pdf.

Persson, L., Sträng, M. \& Antal, I. 2001. Bedrock map 10I Stockholm, scale 1:100 000. Sveriges geologiska undersökning Ba 60. Popov, Y.A., Pribnow, D.F.C., Sass, J.H., Williams, C.F. \& Burkhardt, H. 1999. Characterization of rock thermal conductivity by bigh-resolution optical scanning. Geothermics 28, 253-276. 
Raymond, J., M. Malo, L. Lamarche, L. Perozzi, E. Gloaguen, C. Bégin. 2017. New methods to spatially extendd thermal response test assessments. IGSHPA Technical/Research Conference and Expo. Denver, United States: 256-265. March 14-16.

Schwarz, G., Göransson, M., Tunholm, B. \& Förster, A. 2010. Mapping thermal conductivity of the Swedish bedrock. 29th Nordic Geological Winter Meeting, Oslo. NGF abstracts and proceedings 1, s. 177. 